\title{
Toxicity in Neuronal Cells Caused by Cerebrospinal Fluid from Pneumococcal and Gram-Negative Meningitis
}

\author{
Martin G. Täuber, Meena Sachdeva, \\ Stephen L. Kennedy, Hansruedi Loetscher, \\ and Werner Lesslauer
}

\author{
Microbial Pahogenesis Unit, San Francisco General Hospital, and \\ Department of Medicine, University of California, San Francisco; \\ F. Hoffmann-La Roche, Basel, Swizerland
}

\begin{abstract}
To identify neurotoxic factors in meningitis, a neuronal cell line (HN33.1) was exposed to cerebrospinal fluid (CSF) obtained from rabbits with pneumococcal meningitis or Escherichia coli meningitis or $2 \mathrm{~h}$ and $6 \mathrm{~h}$ after meningitis was induced by proinflammatory bacterial products (pneumococcal cell walls, endotoxin). CSF from all types of meningitis induced similar degrees of cytotoxicity. When a soluble tumor necrosis factor (TNF) receptor that completely blocked TNF-mediated toxicity at $10^{-7} M$ was used, all toxicity in meningitis caused by $E$. coli, endotoxin, or pneumococcal cell wall administration ( $2 \mathrm{~h}$ afterwards) was mediated by TNF. In contrast, CSF from animals with meningitis caused by live pneumococci or pneumococcal cell wall injection ( $6 \mathrm{~h}$ afterwards) retained cytotoxicity in the presence of the TNF receptor. Thus, in established pneumococcal meningitis, but not in the other forms of meningitis, TNF is not the only component toxic in this neuronal cell line.
\end{abstract}

Brain damage is the most important complication in survivors of bacterial meningitis. The spectrum of sequelae includes mental retardation, learning disabilities, and focal neurologic deficits, indicating that meningitis causes injury to neurons $[1,2]$. Little is known about the processes leading to neuronal injury. Both ischemia and toxic effects of factors generated by the inflammation in the subarachnoid space have been implicated in contributing to neuronal dysfunction and injury [3-5]. However, it is difficult to identify the role of potential neurotoxic factors in vivo in a disease that results in highly complex pathophysiologic changes.

To study neuronal injury during meningitis, we developed a new approach that combines in vitro and ex vivo elements. The studies were designed to test the hypothesis that soluble factors generated by the infection and inflammation during meningitis contribute to neuronal injury. We assumed that such neurotoxic factors, in addition to acting directly on neurons, are released into the cerebrospinal fluid (CSF), thus allowing us to use CSF from animals with meningitis as the source. We used a murine neuronal cell line (HN33.1) [6], which shows important neuron-specific characteristics, and a soluble TNF receptor [7] to examine whether infected CSF contains cytotoxic factors. CSF from animals with meningitis

Received 16 March 1992: revised 22 May 1992.

Presented in part: 31 st Interscience Conference on Antimicrobial Agents and Chemotherapy, Chicago, September-October 1991.

M.G.T. is a stockholder and H.L. and W.L. are employees of Roche Inc.

Grant support: Academic Senate Committec on Research. University of California, San Francisco (to M.G.T.).

Reprints or correspondence: Dr. Martin Täuber, Microbial Pathogenesis Unit. Box 0811. University of California, San Francisco, 3rd and Parnassus Ave., San Francisco, CA 94143.

The Journal of Infectious Diseases 1992;166:1045-50 (C) 1992 by The University of Chicago. All rights reserved. $0022-1899 / 92 / 6605-0013 \$ 01.00$ induced by both gram-positive and gram-negative live organisms and by proinflammatory bacterial components was examined in the cell culture system.

\section{Material and Methods}

Experimental meningitis. Meningitis was induced in New Zealand White rabbits, $2-3 \mathrm{~kg}$, by various stimuli as described below. Animals were anesthetized with an intramuscularly administered mixture of acepromazine, $0.5-1.0 \mathrm{mg} / \mathrm{kg}$ (Promace; Aveco, Fort Dodge, IA), ketamine, $35-50 \mathrm{mg} / \mathrm{kg}$ (Ketaset; Bristol Laboratories, Syracuse, NY), and xylazine, $2-5 \mathrm{mg} / \mathrm{kg}$ (Gemini; Rugby Laboratories, Rockville, NY). The cisterna magna was directly punctured by a 25 -gauge butterfly needle, and 0.3 $\mathrm{mL}$ of the inoculum was injected into the CSF. After the time intervals indicated below, animals were anesthetized again, and inflamed CSF was collected by a second puncture of the cisterna magna (0.5-1.0 mL of CSF/animal). CSF was immediately centrifuged at $8000 \mathrm{~g}$ for $5 \mathrm{~min}$, pooled for groups of 5-8 animals, and stored at $-70^{\circ} \mathrm{C}$. The severity of meningitis was quantitated in pooled CSF by determining CSF lactate and glucose concentrations [8] with an automatic lactate/glucose analyzer (2300 STAT; Yellow Springs Instruments, Yellow Springs, OH). Sterility of the samples before use in the cell culture system was confirmed by culturing $0.1 \mathrm{~mL}$ on blood agar plates.

Live pneumococcal meningitis. Streptococcus pneumoniae type 3 was used to produce meningitis [8]. The organism was grown on blood agar plates, harvested in saline, and stored at $-70^{\circ} \mathrm{C}$. To induce meningitis, the inoculum was thawed and diluted to $10^{6} \mathrm{cfu} / \mathrm{mL}$ in normal saline. Eighteen hours after intracisternal injection of the inoculum, when animals showed signs of disease (fever, lethargy), a single dose of ceftriaxone $(150 \mathrm{mg} / \mathrm{kg})$ was administered through an ear vein to treat meningitis. Three hours later, CSF was collected and processed as described above. In control experiments designed to examine whether in vitro growth of pneumococci in CSF produced prod- 
ucts that were toxic to HN33.1 cells, $S$. pneumoniae was grown for $6 \mathrm{~h}$ in vitro in normal rabbit CSF. Subsequently, the culture was sterilized by adding $10 \mu \mathrm{g} / \mathrm{mL}$ ceftriaxone for $4 \mathrm{~h}$, followed by centrifugation ( $8000 \mathrm{~g}$ for $10 \mathrm{~min}$ ) to remove residual bacteria. In a second preparation, cultures were centrifuged $(8000 \mathrm{~g}$ for $10 \mathrm{~min}$ ) and pneumococci were then disrupted by vigorous sonication. In both cases, sterility of the preparation was confirmed before the experiments in the cell culture system. In addition, control experiments using filter sterilization of CSF with 0.2- $\mu \mathrm{m}$ filters (Sterile Acrodisc; Gelman Sciences, Ann Arbor, MI) showed no effect of the filtration step on the cytotoxicity induced by CSF from animals with pneumococcal meningitis.

Meningitis induced by pneumococcal cell wall. Pneumococcal cell walls were prepared as described by Tuomanen et al. [9]. Briefly, a rough strain of $S$. pneumoniae (R6) was grown in Todd-Hewitt medium to stationary phase, harvested in saline, and boiled for $15 \mathrm{~min}$ to inactivate autolytic enzymes. Bacterial cells were then disrupted using glass beads. The resulting crude cell wall preparation was washed twice in boiling $2 \%$ SDS, incubated with DNase, RNase, and trypsin, extensively washed in distilled water, suspended in saline, and stored at $-70^{\circ} \mathrm{C}$. Cell wall preparation (10-30 $\mu \mathrm{g}$, equivalent to $\sim 10^{8} \mathrm{cfu}$ ) was injected intracisternally in $0.3 \mathrm{~mL} ; 2$ and $6 \mathrm{~h}$ later, CSF was collected and processed as described above. In control experiments, the same cell wall preparation was added to the cell culture medium.

Live Escherichia coli meningitis. A Kl-positive strain of $E$. coli was used for these experiments. The organism was grown in trypticase soy broth to logarithmic phase, washed, and resuspended in saline, and rabbits were injected intracisternally with $2 \times 10^{6} \mathrm{cfu}$; $14 \mathrm{~h}$ later, when animals were clinically ill, antibiotic treatment was initiated with one intravenous dose of ceftriaxone or cefotaxime ( $150 \mathrm{mg} / \mathrm{kg}$ ). Three hours later, CSF was collected and processed as described above. In control experiments, supernatants from $E$. coli cultures grown in vitro in CSF were used after sterilization of the culture with $10 \mu \mathrm{g} / \mathrm{mL}$ ceftriaxone and centrifugation ( $8000 \mathrm{~g}$ for $5 \mathrm{~min}$ ).

Meningitis induced by endotoxin. Endotoxin from rough Salmonella minnesota Re 595 was purchased from Sigma (St. Louis). Stock solutions were prepared by suspending $10 \mathrm{mg}$ of endotoxin in $2 \mathrm{~mL}$ of $20 \mathrm{mM}$ EDTA, followed by sonification. Aliquots were kept at $-70^{\circ} \mathrm{C}$. To induce meningitis, stock solution was diluted $1: 100$ in saline and filter sterilized $(0.2-\mu \mathrm{m}$ filters), and $10 \mu \mathrm{g}$ of endotoxin was injected intracisternally; 2 and $6 \mathrm{~h}$ later CSF pools were generated. The identical endotoxin preparation was also used directly in the cell culture system at a concentration of $30 \%$ ( vol/ $\mathrm{vol})$.

Other reagents. Recombinant human (rh) TNF $\alpha$ was a gift from Genentech (South San Francisco). Stock solutions were made in saline containing $0.2 \%$ bovine serum albumin and kept at $4^{\circ} \mathrm{C}$. Appropriate final concentrations were prepared in culture medium. Recombinant human soluble TNF receptor consisted of the extracellular portion of the $55-\mathrm{kDa}$ human TNF receptor, as previously described $[7,10]$. Recombinant human interleukin- $1 \alpha$ (rhIL-1 $\alpha$ ) was a gift from Hoffmann-La Roche (Nutley, NJ). Stock solutions in distilled water were kept at $4^{\circ} \mathrm{C}$, and final concentrations were prepared in culture medium. Glutamate was purchased from Sigma, and solutions were prepared freshly for each experiment in culture medium. Arachidonic acid was purchased from Sigma and was dissolved in KrebsRinger buffer to yield a $1 \mathrm{~m} M$ concentration.

Neuronal cell line HN33.I. This cell line was generated by the fusion of hippocampal neurons from young adult mice with a neuroblastoma cell line (gift of B. Wainer, University of Chicago) [6]. HN33. I cells show important features characteristic of neurons, such as the presence of neuritic processes, neurofilament protein, and membrane excitability typical for hippocampal neurons. In these regards the cell line is distinct from the neuroblastoma parent cell line [6]. HN33.1 cells were grown in Dulbecco's modified Eagle medium (DMEM) supplemented with $10 \%$ fetal calf serum and 100 units/mL penicillin $G$ and $100 \mu \mathrm{g} / \mathrm{mL}$ streptomycin in tissue culture 96-well microtiter plates (Falcon Primaria; Becton Dickinson, Lincoln Park, NJ) at $37^{\circ} \mathrm{C}$ in room air containing $5 \% \mathrm{CO}_{2}$. When the cells reached $75 \%-90 \%$ confluence, the culture medium was changed to fresh medium and the cells were exposed to the various stimuli for 48 $h$. The highest concentration of CSF and bacterial supernatants examined in these experiments was $30 \%$ (vol/vol). All experiments were done in triplicate wells, and culture medium alone and native CSF were included as controls.

Cytotoxicity assay. Cytotoxicity was assessed by measuring leakage of lactate dehydrogenase (LDH) into the culture supernatant by a commercial assay (Sigma). Centrifuged medium $(100 \mu \mathrm{L})$ from each cell culture well was added to $1 \mathrm{~mL}$ of reagent solution according to the manufacturer's instructions, and the reduction of NAD resulting from oxidation of lactate to pyruvate was measured at $340 \mathrm{~nm}$ on a spectrophotometer (DU70; Beckmann, Duarte, CA). LDH contained in the culture medium (mean, 59 units $/ \mathrm{mL}$ ) and in CSF-containing medium (mean, 115 units/mL for live pneumococcal meningitis, the pool with the highest LDH content) was subtracted and the net LDH release was then expressed as percentage of control wells ( $\mathrm{LDH}$ releases in control wells $=100 \%$ ). Cytotoxicity was routinely confirmed in all experiments by simultaneous microscopic quantitation of dead cells stained with $0.4 \%$ trypan blue for $5 \mathrm{~min}$.

Statistics. Results of an individual experiment were calculated as mean \pm SD for triplicate wells. Results presented here are mean \pm SD of four to eight independent experiments. Comparison between groups was done by Student's $t$ test, adjusted for multiple comparisons by the Bonferroni correction. Data that did not show a normal distribution were analyzed by the Mann-Whitney rank sum test.

\section{Results}

Characteristics of CSF pools. Infection with either $S$. pneumoniae or $E$. coli produced profound inflammatory changes in the CSF, with polymorphonuclear pleocytosis and markedly increased lactate concentrations and reduced glucose concentrations (table 1). Lactate concentrations were higher in animals infected with $E$. coli than in animals infected with $S$. pneumoniae $(P<.01)$, while glucose concentrations were similar. Lactate and glucose concentrations in CSF $2 \mathrm{~h}$ after intracisternal injection of pneumococcal cell 
Table 1. Lactate and glucose concentrations in CSF pools from rabbits with different forms of bacterial meningitis.

\begin{tabular}{lcc}
\hline Pool $(n)$ & $\begin{array}{c}\text { Lactate } \\
\text { (mmol/L) }\end{array}$ & $\begin{array}{c}\text { Glucose } \\
(\mathrm{mg} / 100 \mathrm{~mL})\end{array}$ \\
\hline $\begin{array}{l}\text { Normal controls (6) } \\
\text { Pneumococcal meningitis }\end{array}$ & $1.7 \pm 0.2^{*}$ & $116 \pm 4$ \\
$\quad$ Live Streptococcus pneumoniae (5) & $11.2 \pm 1.9^{\dagger}$ & $71 \pm 36^{\ddagger}$ \\
$\quad$ Cell wall 2 h (4) & $2.9 \pm 0.8$ & $146 \pm 15^{\ddagger}$ \\
Cell wall 6 h (4) & $8.3 \pm 1.5$ & $114 \pm 24$ \\
Gram-negative meningitis & & \\
Live Escherichia coli (3) & $14.5 \pm 1.6^{\dagger}$ & $70 \pm 24^{\ddagger}$ \\
LPS 2 h (4) & $3.2 \pm 0.4$ & $105 \pm 20$ \\
LPS 6 h (4) & $9.7 \pm 1.5$ & $80 \pm 45^{\ddagger}$ \\
\hline
\end{tabular}

NOTE. LPS $=$ lipopolysaccharide, $n=$ no. of CSF pools used.

${ }^{*} P<.01$ vs. all meningitic CSF.

$+P<.01$.

$\ddagger P<.01$ vs. controls.

wall or endotoxin showed only mild abnormalities compared with normal control levels (table 1). These CSF pools, however, contain high concentrations of various cytokines, including TNF at $\sim 2 \times 10^{-9} M$ concentration, IL-1, and IL-6 [11-13]. Four hours later, both bacterial stimuli had induced a typical inflammatory response, with CSF pleocytosis and markedly increased lactate concentrations that were similar to those found in animals infected with live organisms (table 1). Pneumococcal cell wall did not cause a reduction in CSF glucose concentrations, while endotoxin did (table 1).

Cytotoxicity induced by pools of infected CSF. CSF from all six types of meningitis produced substantial cytotoxicity in HN33.1 cells when the cells were exposed to culture medium containing $30 \% \mathrm{CSF}$ (vol/vol) for $48 \mathrm{~h}$. Net LDH release averaged 40.5 units $/ \mathrm{mL}$ of supernatant in control wells and increased to 311.3 units $/ \mathrm{mL}$ in wells exposed to CSF from animals with live pneumococcal meningitis. Values for other CSF pools were similar, and LDH release, when normalized for controls, increased by $\sim 600 \%-900 \%$ (table 2 ). There was no significant difference in the degree of cytotoxicity between the six CSF preparations examined (table 2). Results of LDH measurements were confirmed by examination of the cultures after trypan blue staining, with at least $30 \%-50 \%$ of the exposed cell showing evidence of injury, while $<1 \%$ of control cells were trypan blue-positive. Native CSF at $30 \%$ (vol/vol) and CSF from infected animals at concentrations of $<10 \%$ (vol/vol) did not lead to increased LDH release or evidence of injury by trypan blue staining, while there was increasing toxicity at concentrations of $15 \%-30 \%$ ( $\mathrm{vol} / \mathrm{vol}$ ) of infected CSF. Filter sterilization of the CSF pools did not affect the degree of cytotoxicity.

Effect of soluble TNF receptor on cytotoxicity of meningitic $C S F$. We found that rhTNF $\alpha$ at concentrations as low as 5 $\times 10^{-11} M$ induced significant release of LDH from HN33.1 cells, while maximal LDH release was induced by $5 \times 10^{-8}$
$M$. Since CSF from animals with experimental meningitis due to various bacterial stimuli has been shown to contain $\sim 10^{-9} M$ TNF $\alpha$ [11-13], we used a soluble TNF receptor to determine to what extent the cytotoxicity of CSF could be accounted for by the presence of TNF [7]. Experiments with rhTNF showed that between 10- and 100-fold molar excess of the receptor completely blocked the cytotoxicity of rhTNF $\alpha$ (table 2). We therefore used the receptor at $10^{-8}$ and $10^{-7} M$ concentrations in the experiments with CSF from rabbits with meningitis. The receptor alone was not toxic when added to the culture. At the higher concentration examined, the receptor completely blocked the cytotoxicity of CSF from animals with meningitis caused by $E$. coli, endotoxin, or injection of pneumococcal cell wall (after $2 \mathrm{~h}$ ) (table 2). In contrast, cytotoxicity of CSF from animals with $S$. pneumoniae meningitis was only partially blocked by the receptor $(P<.001$ compared with rhTNF) (table 2$)$. Cytotoxicity from CSF obtained $6 \mathrm{~h}$ after injection of pneumococcal cell wall was also not completely blocked by the TNF receptor $(P=.01$ vs. rhTNF) (table 2$)$.

Cytotoxicity of bacterial products. Since CSF from animals with pneumococcal but not gram-negative meningitis seemed to contain a factor other than TNF that is cytotoxic for HN33. 1 cells, we examined whether various sterile preparations obtained from pneumococcal cultures were toxic to the cell line in vitro. Adding the cell wall preparation used to produce meningitis at $30 \%(\mathrm{vol} / \mathrm{vol})$ to the cell culture led to an increased release of LDH to $250.1 \% \pm 26.8 \%$ of controls $(P<.01)$, while concentrations of $\leqslant 20 \%$ were not toxic. In contrast, CSF in which pneumococci had been grown in vitro and then killed by antibiotics, pneumococci disrupted by sonication, or rough, heat-killed pneumococci (strain R6)

Table 2. Lactate dehydrogenase (LDH) release from HN33.1 cells after exposure to recombinant human tumor necrosis factor ( $r$ TNF $\alpha$ ) or CSF from various forms of meningitis in the absence or presence of soluble TNF receptor.

\begin{tabular}{lccc}
\hline & \multicolumn{4}{c}{ Receptor concentration } \\
\cline { 2 - 4 } Stimulus & None $(n)$ & $10^{-8} M(n)$ & $10^{-7} M(n)$ \\
\hline rhTNF $\alpha\left(10^{-9} M\right)$ & $534 \pm 237(8)$ & $136 \pm 71(8)$ & $74 \pm 20(4)^{*}$ \\
$\begin{array}{l}\text { Meningitic CSF (30\%) } \\
\text { Live Sireptococus }\end{array}$ & & & \\
$\quad$ pneumoniae & $750 \pm 378(9)$ & $334 \pm 152(9)^{\dagger}$ & $323 \pm 122(6)^{\dagger}$ \\
Cell wall 2 h & $995 \pm 257(6)$ & $113 \pm 38(6)$ & $80 \pm 43(3)$ \\
Cell wall 6 h & $779 \pm 307(9)$ & $279 \pm 205(9)^{*}$ & $248 \pm 205(6)^{*}$ \\
Live Escherichia & & & \\
$\quad$ coli & $713 \pm 271(7)$ & $113 \pm 41(7)$ & $108 \pm 9(4)$ \\
LPS 2 h & $705 \pm 445(4)$ & $57 \pm 43(4)$ & $\mathrm{ND}$ \\
LPS 6 h & $896 \pm 396(7)$ & $106 \pm 62(7)$ & $90 \pm 43(4)$ \\
\hline
\end{tabular}

NOTE. Data are \% of control. LPS $=$ lipopolysaccharide; $n=$ no. of independent experiments. $\mathrm{ND}=$ not done.

$+P<.009$ vs. other groups except cell wall $6 \mathrm{~h}$.

${ }^{*} P=.01$ (by Mann-Whitney rank sum). 
were not toxic at the highest concentrations examined $\left(\sim 10^{7} \mathrm{cfu} / \mathrm{mL}\right.$, corresponding to the CSF titers in vivo). Endotoxin at $10 \mu \mathrm{g} / \mathrm{mL}$ and CSF in which $E$. coli had been grown in vitro at $30 \%(\mathrm{vol} / \mathrm{vol})$ concentrations also were not toxic.

Cytotoxicity of other components of infected CSF. Components of infected CSF that can potentially be cytotoxic include cytokines other than TNF (e.g., interleukins), excitatory amino acids (glutamate and aspartate), and arachidonic acid released from neutrophil cell membranes. IL- $1 \alpha$ at concentrations up to $10^{-8} M$ and the excitatory amino acid glutamate at concentrations up to $1 \mathrm{~m} M$ were not toxic to HN33. 1 cells. Arachidonic acid at $1 \times 10^{-3} \mathrm{M}$ and 5 $\times 10^{-4} M$ led to significant increases in LHD $(359.3 \% \pm$ $11.9 \%$ and $230.1 \% \pm 35.3 \%$ of controls, respectively; $P<$ $.01)$, while lower concentrations were not toxic.

\section{Discussion}

The spectrum of neurologic sequelae caused by bacterial meningitis provides good evidence for the occurrence of neuronal injury during meningitis. Work in animal models has provided insights into the molecular mechanisms of inflammation and into the pathophysiology of the disease $[4,5]$, but in general animal models have not conclusively demonstrated a causal relationship between these changes and neuronal injury. The main purpose of the present studies was therefore to develop an in vitro approach to examine the process of neuronal injury during bacterial meningitis.

Clinical studies showing a beneficial effect of dexamethasone in children with bacterial meningitis $[14,15]$ and animal studies indicate that components of the inflammation generated during meningitis contribute to brain injury [1618]. These observations prompted us to explore in vitro the presence of cytotoxic factors generated during meningitis. Since the primary site of infection and inflammation in meningitis is the subarachnoid space, we examined CSF from animals with meningitis. Ultimately, it will be necessary to show in vivo that cytotoxic factors identified in the CSF during meningitis produce their toxic effects on neurons within brain tissue. However, there are clearly similarities between the disease process in the subarachnoid space and events in the brain. In both animal models and humans with meningitis the inflammatory process is not confined to the subarachnoid space but involves focal areas of the brain, thereby generating inflammatory products directly within brain tissue [19-21]. Furthermore, proteins can diffuse from the CSF into the brain [22]. This diffusion likely explains why the injection of cytokines into the CSF of experimental animals has profound effects on the brain and induces diffuse brain edema [17].

We induced meningitis with both live organisms and products of these meningeal pathogens that are responsible for initiating the inflammatory response during meningitis $[9$,
23] to examine whether our system detected biologic differences between, for example, pneumococcal and $E$. coli meningitis or between meningitis induced by live organisms and by sterile bacterial products. We were initially surprised that CSF from animals with all forms of meningitis was neurotoxic in vitro to very similar degrees, despite the fact that changes in the CSF formula were much less pronounced $2 \mathrm{~h}$ after intracisternal injection of a sterile bacterial stimulus than they were $20 \mathrm{~h}$ after induction of meningitis by live organisms. However, the results can be explained by the importance of TNF in this system that used a TNF-sensitive cell line. Cytokines in the CSF peak $\sim 2 \mathrm{~h}$ after intracisternal injection of proinflammatory bacterial products, and after 6 $h$ the concentrations are still in a range cytotoxic for HN33.1 cells $[11,12]$. In animals with meningitis induced by live organisms, TNF concentrations are especially high shortly after beginning antibiotic therapy, which leads to increased release of TNF through the liberation of bacterial products $[11,24,25]$. Thus, all CSF samples tested in our study contained high TNF concentrations sufficient to induce close to maximal cytotoxicity in the HN33. 1 cells.

The use of a soluble 55-kDa TNF receptor proved to be a valuable tool to further examine the cytotoxicity of infected CSF in our in vitro model $[7,10]$. The complete blockage of the cytotoxicity of rabbit TNF in inflamed CSF by the human receptor molecule documented that the neutralizing capacity of the receptor was less susceptible to species variations of the TNF molecule than was a mouse monoclonal antibody (provided by Cutter Laboratories, Berkeley, CA), which effectively neutralized rhTNF $\alpha$ in our system but was ineffective in blocking the cytotoxicity of CSF from rabbits with meningitis (data not shown). The results obtained with the receptor indicate that TNF was the only component toxic to the HN33. 1 cells in the CSF from animals with meningitis caused by gram-negative stimuli (live bacteria and endotoxin) and early after the induction of meningitis by pneumococcal cell wall. In contrast, significant cytotoxicity remained despite high doses of TNF receptor in CSF from animals with established pneumococcal meningitis. This suggests a fundamentally different neurotoxic potential in pneumococcal than in gram-negative meningitis. It remains to be determined whether this non-TNF-mediated cytotoxicity of pneumococcal meningitis contributes to the high rate of central nervous system injury and mortality observed in pneumococcal meningitis [26-28].

The reasons for the different cytotoxic profiles of pneumococcal and $E$. coli meningitis are unclear. CSF inflammation was not more pronounced in pneumococcal meningitis, and TNF concentrations in CSF during pneumococcal meningitis are not higher than in $E$. coli meningitis (Tureen $\mathrm{JH}$, Lau A, personal communication). Also, the difference apparently is not explained by direct toxicity of components derived from pneumococci. The fact that non-TNF-mediated toxicity could be induced by the cell wall preparation indi- 
cates that bacterial products such as pneumolysin or lipoteichoic acid were not responsible for this cytotoxicity, since they are inactivated during preparation of the cell walls. This is also supported by the lack of toxicity of supernatants of mechanically disrupted or lysed pneumococci. Pneumococcal cell walls showed some toxicity in vitro, but the cytotoxic concentration of these fragments was at least 10 times higher than that in CSF, and CSF obtained $6 \mathrm{~h}$ after intracisternal injection of the pneumococcal cell wall but not the 2-h sample with the higher cell wall concentration contained the non-TNF-mediated cytotoxic component. While these results cannot conclusively rule out a role of a pneumococcal factor in the non-TNF-mediated toxicity, they are compatible with the hypothesis that pneumococci, but not gramnegative bacterial stimuli, induce a host factor other than TNF that is cytotoxic in the HN33. 1 cells. The nature of this factor is unclear, but several candidates seem unlikely on the basis of our results. IL-1 is one of the cytokines found in the CSF during meningitis $[12,29]$, and in human macrophages pneumococcal cell walls are more potent stimuli of IL-I than is endotoxin [30]. However, IL-1 failed to show any cytotoxicity in HN33.1 cells. Excitatory amino acids such as glutamate can cause neuronal injury via $N$-methyl-D-aspartate receptors [31] and are increased in the CSF during meningitis (unpublished data), but HN33.1 cells are resistant to glutamate. Finally, we examined arachidonic acid because of its known cytotoxic effect on neurons [32,33], but the concentrations that were cytotoxic to HN33.1 cells far exceeded those that can be expected in infected CSF.

The identification of a cytotoxic factor associated with pneumococcal meningitis poses several interesting questions to be addressed in future studies. The chemical identity of this factor and its specificity for cells of neuronal origin will have to be worked out. Furthermore, it will be important to examine this factor in primary neuronal cultures that may be more indicative of the situation in vivo than the cell line used here. Finally, once the neurotoxic factor is identified, we hope to be able to determine its role in causing neuronal injury in vivo.

\section{Acknowledgment}

We thank Daniel H. Lowenstein for helpful comments.

\section{References}

I. Klein JO, Feigin RD, McCracken GHJ. Report of the task force on diagnosis and management of meningitis. Pediatrics 1986;78:95982.

2. Sell SHW, Webb WW, Pate JE, Doyne EO. Physiological sequelae to bacterial meningitis: two controlled studies. Pediatrics 1972;49:2127.

3. Tureen JH, Dworkin RJ, Kennedy SL, Sachdeva M, Sande MA. Loss of cerebrovascular autoregulation in experimental meningitis in rabbits. $J$ Clin Invest 1990;85:577-81.
4. Saez-Llorens X, Ramilo O, Mustafa MM, Mertsola J, McCracken GH. Molecular pathophysiology of bacterial meningitis: current concepts and therapeutic implications. J Pediatr 1990;116:671-84.

5. Sande MA, Täuber MG, Scheld WM, McCracken GHJ, Pathophysiology of bacterial meningitis. Summary of the workshop. Pediatr Infect Dis J 1989;8:929-33.

6. Lee HJ, Hammond DN, Large TH, et al. Neuronal properties and trophic activities of immortalized hippocampal cells from embryonic and young adult mice. J Neurosci 1990;10:1779-87.

7. Loetscher HR, Gentz R, Zulauf M, et al. Recombinant $55 \mathrm{kDa}$ TNF receptor. Stoichiometry of binding to TNF $\alpha$ and TNF $\beta$, and inhibition of TNF activity. J Biol Chem 1991;266:18324-9.

8. Täuber MG, Burroughs M, Niemöller UM, Kuster H, Borschberg U, Tuomanen E. Differences of pathophysiology in experimental meningitis caused by three strains of Sireptococcus pneumoniae. J Infect Dis 1991;163:806-11.

9. Tuomanen E, Tomasz A. Hengstler B, Zak O. The relative role of bacterial cell wall and capsule in the induction of inflammation in pneumococcal meningitis. J Infect Dis 1985;151:535-40.

10. Loetscher H, Pan YCE, Lahm HW, et al. Molecular cloning and expression of the human $55 \mathrm{kd}$ tumor necrosis factor receptor. Cell 1990;61:351-9.

11. Mustafa MM, Ramilo O, Olsen KD, et al. Tumor necrosis factor- $\alpha$ in mediating experimental Haemophilus influenzae type b meningitis. J Clin Invest 1989;84:1253-9.

12. Waage A, Halstensen A, Shalaby R, Brandtz P. Kierule P, Espevik T: Local production of tumor necrosis factor- $\alpha$, interleukin 1 , and interleukin 6 in meningococcal meningitis. J Exp Med 1989;170:185967

13. Arditi M. Manogue KR, Caplan M, Yogev R. Cerebrospinal fluid cachectin/tumor necrosis factor- $\alpha$ and platelet-activating factor concentrations and severity of bacterial meningitis in children. $J$ Infect Dis 1990;162:139-47.

14. Lebel MH, Freij BJ, Syrogiannopoulos GA, et al. Dexamethasone therapy for bacterial meningitis. Results of two double-blind, placebocontrolled trials. N Engl J Med 1988;319:364-7I.

15. Odio CM, Faingezicht I, Paris M, et al. The beneficial effects of early dexamethasone administration in infants and children with bacterial meningitis. N Engl J Med 1991;324:1525-31.

16. Nolan CM, McAllister CK, Walters E, Beaty HN. Experimental pneumococcal meningitis. IV. The effect of methyl prednisolone on meningeal inflammation. J Lab Clin Med 1978;91:979-88.

17. Saukkonen $\mathrm{K}$, Sande $\mathrm{S}$, Cioffe $\mathrm{C}$, et al. The role of cytokines in the generation of inflammation and tissue damage in experimental grampositive meningitis. J Exp Med 1990;171:439-48.

18. Tuomanen EI, Saukkonen K, Sande S, Cioffe C, Wright SD. Reduction of inflammation, tissue damage, and mortality in bacterial meningitis in rabbits treated with monoclonal antibodies against adhesion-promoting receptors of leukocytes. J Exp Med 1989;170:959-68.

19. Täuber MG, Kennedy SL, Tureen JH, Lowenstein DH. Experimental pneumococcal meningitis causes central nervous system pathology without inducing the $72 \mathrm{kDa}$ heat shock protein. Am J Pathol 1992;141:53-60.

20. Cairns H, Russell DS. Cerebral arteritis and phlebitis in pneumococcal meningitis. J Pathol Bacteriol 1946;58:649-65.

21. Branham SE, Lillie RD. Observations on experimental meningitis in rabbits. Public Health Rep 1932;47:2137-50.

22. Rennels M, Gregory TF, Blaumanis OR, Fujimoto K. Grady P. Evidence for a "paravascular" fluid circulation in the mammalian central nervous system, provided by the rapid distribution of tracer protein throughout the brain from the subarachnoid space. Brain Res 1985;326:47-63.

23. Syrogiannopoulos GA, Hansen EJ, Erwin AL, et al. Haemophilus in 
fluenzae type b oligosaccharide induces meningeal inflammation. $\mathrm{J}$ Infect Dis 1988;157:237-44.

24. Täuber MG, Shibl AM, Hackbarth CJ, Larrick JW, Sande MA. Antibiotic therapy, endotoxin concentration in cerebrospinal fluid, and brain edema in experimental Escherichia coli meningitis in rabbits. J Infect Dis 1987;156:456-62.

25. Tuomanen E, Hengstler B, Rich R, Bray MA, Zak O, Tomasz A. Nonsteroidal anti-inflammatory agents in the therapy for experimental pneumococcal meningitis. J Infect Dis 1987;155:985-90.

26. Dodge PR, Hallowell D, Feigin RD, et al. Prospective evaluation of hearing impairment as a sequela of acute bacterial meningitis. $N$ Engl J Med 1984;31 1:869-74.

27. Bryan JP, de Silva HR, Tavares A, Rocha H. Scheld WM. Etiology and mortality of bacterial meningitis in northeastern Brazil. Rev Infect Dis 1990; 12 : 128-35.

28. Wenger JD, Hightower AW, Facklam RR, Gaventa S, Broome CV, Bacterial Meningitis Study Group. Bacterial meningitis in the United
States, 1986: report of a multistate surveillance study. I Infect Dis 1990;162:1316-23.

29. McCracken GHJ, Mustafa MM, Ramilo O, Olsen KD, Risser RC. Cerebrospinal fluid interleukin 1-beta and tumor necrosis factor concentrations and outcome from neonatal gram-negative enteric bacillary meningitis. Pediatr Infect Dis J 1989;8: I 55-9.

30. Riesenfeld-Orn I, Wolpe S, Garcia-Busto JF, Hoffman MK, Tuomanen E. The production of interleukin-1 but not tumor necrosis factor by human monocytes stimulated with pneumococcal surface components. Infect Immun 1989;57:1890-3.

31. Choi DW. Glutamate neurotoxicity and disease of the nervous system. Neuron 1988; 1:623-34.

32. Chan PH, Schmidley JW, Fishman RA, Longar SM. Brain injury, edema, and vascular permeability changes induced by oxygen derived free radicals. Neurology 1984;34:315-20.

33. Chan PH, Fishman RA. The role of arachidonic acid in vasogenic brain edema. Fed Proc 1984;43:210-3. 